\title{
ADHD in international adoptees: a national cohort study
}

\author{
Frank Lindblad · Gunilla Ringbäck Weitoft • \\ Anders Hjern
}

Received: 31 October 2008/ Accepted: 26 May 2009/Published online: 19 June 2009

(C) Springer-Verlag 2009

\begin{abstract}
Several investigators have reported an increased frequency of attention/hyperactivity symptoms in international adoptees, though population-based studies are lacking. In this national cohort study, we aimed to determine the prevalence of ADHD medication in international adoptees in Sweden, in comparison to the general population. A further purpose was to study gender, age at adoption and region of origin as predictors of ADHD medication in international adoptees. The study population consisted of all Swedish residents born in 1985-2000 with Swedish-born parents, divided into 16,134 adoptees, and a comparison population of $1,326,090$. ADHD medications were identified in the Swedish Prescribed Drug Register during 2006. Logistic regression was used to calculate the odds ratios. The rates of ADHD medication were higher in international adoptees than in the comparison population for both boys (5.3 vs. $1.5 \%$ for $10-15$-year olds) and girls ( 2.1 vs. $0.3 \%$ for $10-15$-year olds). International adoptees from all regions of birth more often consumed ADHD medication compared with the majority population, but the
\end{abstract}

F. Lindblad $(\bowtie)$

Department of Neuroscience, Child and Adolescent Psychiatry,

Uppsala University, 75185 Uppsala, Sweden

e-mail: frank.lindblad@neuro.uu.se

F. Lindblad

Stress Research Institute, Stockholm University,

10691 Stockholm, Sweden

G. Ringbäck Weitoft · A. Hjern

Centre for Epidemiology, National Board of Health and Welfare, 10630 Stockholm, Sweden

A. Hjern

Department of Women and Children's Health,

Uppsala University, 75185 Uppsala, Sweden age and sex adjusted odds ratios were particularly high for adoptees from Eastern Europe, Middle East/Africa and Latin America. Adjusting for maternal education and single parenthood increased the odds ratios even further. The risk also increased with higher age at adoption. Adoptees from Eastern Europe have a very high risk for ADHD medication. A structured identification and support programme should be tailored for this group. Adoptees from other regions have a more moderately increased risk, which should be communicated to adoptive parents and to professionals who care for adoptees in their clinical practice.

Keywords International adoption - ADHD . Methylphenidate $\cdot$ Atomoxetine $\cdot$ Eastern Europe

\section{Introduction}

The health development of international adoptees has been the focus of many scientific reports. In the largest $(n=2,148)$ study on international adoptees (10-15 years of age) from the last century, Verhulst et al. [1] found a higher frequency of adopted children with psychiatric problems (measured through the parental version of Child Behavior Check List) compared to Dutch non-adopted children of the same age. A follow-up study $(n=1.484)$, using a standardised psychiatric interview procedure, also found higher risk of severe mental health problems [2]. In a series of register studies, using whole national cohorts of 10-15,000 individuals, investigators have reported three- to fourfold greater risks of outcomes related to psychiatric hospitalisations, including suicidal behaviour. Mortality and severe social problems were also observed with similar magnitude of increased risks among international adoptees [3-7]. 
Researchers have long observed the symptoms and syndromes related to hyperactivity, in recent years reported as ADHD, amongst international adoptees. ADHD (attention-deficit hyperactivity disorder) is a neurobehavioural developmental disorder characterised by inattention, impulsiveness and hyperactivity, in different combinations. It is typically a childhood disorder, but a majority $(60-85 \%)$ of children will continue to meet the diagnostic criteria during their teens and several will have remaining problems also as adults [8]. There is considerable evidence that genetic factors are important in the aetiology of ADHD, although the specific genes involved have yet to be identified [9]. Environmental factors may also be influential [10]. Case-control studies have demonstrated an association between psychosocial adversity and ADHD in school children [11, 12]. Foetal alcohol exposure was suggested as one cause of ADHD in the beginning of the 1990s [13]. Bhatara et al. [14] found a $41 \%$ prevalence of ADHD in a sample of 2,231 youths referred for foetal alcohol spectrum disorders.

Verhulst et al. [1] found higher scores for 12- to 15-year-old boys on the delinquent, hyperactive and externalising scales. The English and Romanian Adoptees (ERA) Study Team reported increased risks of attention/ hyperactivity symptoms in Romanian adoptees with a background of institutionalisation [15]. The authors conclude that these types of symptoms may constitute an "institutional deprivation syndrome", but also suggest that these children may present with a different clinical picture than ordinary ADHD types. The ERA team has proposed that institutional deprivation results in early biological programming or neural damage, but has also stated that these effects may be modified by a favourable post-adoption environment [16].

Several studies involving a majority of national adoptees have previously demonstrated greater risks for ADHD. For instance, Simmel et al. [17] performed a parental questionnaire study with a state-wide non-clinical adoptee population, aged 4-18 years, with international adoptees constituting $5 \%$ of the sample. Originally, parents representing 2,589 placements had been invited. After attrition in several steps and exclusions due to specified criteria, 808 adoptees remained. Of these, $21.8 \%$ met the symptom criteria for ADHD. Other reports on risk factors for ADHD amongst adoptees are inconclusive. In the study from the USA by Simmel et al. [17], referring to the above, male gender and later age of adoption were associated with a higher risk. In a comparable sample of 178 British adoptees (probably a vast majority of national adoptees), risks of ADHD were as high for girls as for boys, and age at adoption was not related to the type of psychopathology [18].

Adoptees from Eastern Europe have constituted a large proportion of all intercountry adoptees during the last decade. For instance, in the USA, adoptees from the nations of the former Soviet Union are the second largest group after China [19]. Also in Sweden, historically probably the second largest receiver country after the USA, adoptees from Eastern Europe have increased during the 1990s. Since the middle of the 1990s, European origin has been more common than origin from Latin America http://www.mia.eu/statistik/varlds.pdf. In a Swedish study on Eastern European adoptees from the middle of the 1990s, the authors describe in detail the neuropsychiatric challenges [20]. For instance, 78\% had abnormal ocular findings with visuoperceptual problems in 37 , compared to $1 \%$ in a non-adopted comparison group [21]. At least one-third had been exposed to alcohol prenatally. The frequency of ADHD (identified retrospectively through analyses of records from child health care, school health care and outpatient paediatric care) was three times as high as in a Swedish norm group [20].

Dalen and Rygvold reported that hyperactive behaviour was not more common in a study group of 77 adoptees from China than amongst non-adopted children [22]. Even if hyperactivity is not synonymous with ADHD, the findings illustrate that international adoptees are a heterogenous group and mental health outcomes may vary strongly between and within continents [23]. The prognosis is to a high degree determined by the motives for adoption and quality of care in the countries of origin [23]. Along the same line, studies on outcomes may differ between national and international adoptees [24].

The management of ADHD involves a broad variety of measures, such as pharmacological intervention, behavioural therapy, parental and child psychoeducation, linkage with community supports and specific school interventions [8]. National guidelines for medication of ADHD issued by the Swedish National Board of Health and Welfare state that medication should be reserved for cases where other supportive interventions have failed. Psychostimulants, originally amphetamine but with metylphenidate as the dominating choice today, are usually regarded as the pharmaceutical of choice [25]. Their effects are mediated by an increase of intrasynaptic dopamine, norepinephrine and serotonin [25]. One side effect of psychostimulant medication is a modest reduction in the expected height and weight [26]. This may be of particular importance for international adoptees, especially amongst girls, who have an increased risk of early puberty and short final height [27]. Atomoxetine, a more recently available medication used in the management of ADHD, is designated as a nonpsychostimulant. It inhibits the transport of norepinephrine [28]. The reported efficacy of amoxetine in treatment evaluation studies has been lower than that of psychostimulants. On the other hand, the risk for amoxetine abuse, a risk associated with psychostimulants, has 
been regarded as low [25]). A disadvantage is the increased potential for suicidal ideation [29]. A recent review concludes that atomoxetine may be of value, especially in the presence of comorbid disorders and when treatment with stimulant medication has failed [28].

Some limitations re-occur in many reports on ADHD in adoptees. First, many studies are conducted with clinical samples and do not allow for conclusions about the wider population. Second, many studies have relied on parental reports. Third, attrition problems amongst study subjects are typical.

Swedish national registers offer a potential for overcoming these methodological challenges. Whole age cohorts can be identified and, since July 2005, individual prescriptions of drugs have been registered. This makes it possible to study patient groups who are usually not admitted to in-patient care, but who can be identified through purchase of specific prescribed drugs or groups of drugs. ADHD is such a group, characterised by management based on a few drugs, used exclusively for this indication.

Thus, this study was aimed at determining the prevalence of ADHD medication in international adoptees in Sweden, in comparison to the general population. A further aim was to determine the prevalence of ADHD medication in relation to gender, age at adoption and country of origin.

\section{Methods}

This study was based on Swedish national registers held by the National Board of Health and Welfare and Statistics Sweden. All Swedish residents are assigned a unique tendigit identification (ID) number at birth or on immigration. This ID was used to link information from different register sources. The study was approved by the regional ethics committee in Stockholm.

\section{Study population}

All individuals born between 1985 and 2000, who were alive and registered as residents in Sweden on 31 December 2005, were identified in the register of the total population (RTP). Biological and/or adoptive parents of these individuals were identified in the Multi-Generation Register.

Information on region of birth, date of immigration, sex and year of birth in RTP was linked to the study subjects and their parents. Based on this information, we created two study groups: international adoptees $(N=16,134)$, who fulfilled the criteria of being born outside of western Europe, having at least one Swedish-born adoptive parent, but no biological parent in the multi-generation register, and having entered Sweden before their eighth birthday; and the majority population $(N=1,326,090)$, which consisted of all Swedish-born individuals with at least one Swedish-born biological parent and no adoptive parents in the multi-generation register [30].

Several psychiatric outcomes vary with geographic origin (see above) and age at adoption (3). Any effects of these factors were studied separately. The international adoptees were divided based on the region of birth: Far East, South Asia, Latin America, Eastern Europe and Middle East/Africa (see Table 1). Age at adoption was calculated from the year of birth and year of immigration to Sweden. (Adoption in this sense means the time when a child starts living with the new parents and not the date when the formal adoption procedure is completed). As much as $70 \%$ of the adoptees were adopted before 2 years of age.

\section{Socio-economic variables}

As described in "Introduction", psychosocial factors may influence the development of ADHD. Since families of Swedish international adoptees tend to have higher socioeconomic status than families of non-adoptees $(3,4)$, it is important to adjust for such variables when estimating

Table 1 ADHD medication, based on adoption status, county category and socio-economic indicators (maternal education and single parenthood), ages 6-21 years

\begin{tabular}{lllrl}
\hline & $\begin{array}{l}\text { Boys } \\
\text { Total } N\end{array}$ & $\begin{array}{l}\text { Boys } \\
\text { ADHD \% }\end{array}$ & $\begin{array}{l}\text { Girls } \\
\text { Total } N\end{array}$ & $\begin{array}{l}\text { Girls } \\
\text { ADHD \% }\end{array}$ \\
\hline $\begin{array}{l}\text { Adoption/not } \\
\text { Adoptees }\end{array}$ & 7,777 & 3.83 & 8,357 & 1.44 \\
$\begin{array}{l}\text { Non-adoptees } \\
\text { County category }\end{array}$ & 680,949 & 0.96 & 645,141 & 0.27 \\
County Cat 1 & 74,417 & 1.54 & 70,626 & 0.48 \\
County Cat 2 & 332,461 & 1.04 & 315,267 & 0.32 \\
County Cat 3 & 173,563 & 0.91 & 165,341 & 0.23 \\
County Cat 4 & 108,285 & 0.54 & 102,264 & 0.16 \\
Maternal education & & & & \\
<9 years & 61,007 & 1.70 & 58,083 & 0.48 \\
10-12 & 236,649 & 1.19 & 224,376 & 0.32 \\
13-14 & 158,182 & 0.88 & 150,041 & 0.27 \\
15+ & 227,450 & 0.65 & 215,987 & 0.20 \\
Missing & 5,438 & 1.58 & 5,011 & 0.44 \\
Single parenthood & & & & \\
Yes & 169,462 & 1.54 & 163,481 & 0.45 \\
No & 519,264 & 0.82 & 490,017 & 0.23 \\
Total & 688,726 & 0.99 & 653,498 & 0.29 \\
\hline
\end{tabular}

The counties were classified into four categories, based on the proportion of children who had ADHD medication prescriptions during 2006 
mental health risks. In this study, we chose education of the adoptive mother (the biological mother in the majority population) and lone parenthood as indicators of socioeconomic living conditions. Information on the educational level of the mother, adoptive or biological, in 2005 was obtained through linkage to the Swedish National Education Register. The Swedish National Education Register was established by Statistics Sweden in 1985 and is annually updated with information on the highest formal education attained by each individual, from elementary to postgraduate level. Educational attainment was classified into four categories: having 9 years or less of schooling, representing primary school only; 10-12 years, equivalent to secondary school; 13-14 years i.e. short post-secondary education; and $15+$, representing a university education.

Single parenthood of the household of the study subject was obtained through linkage to the Total Enumeration Income Survey of 2003 (when all study subjects were minors).

Drug variables

The Swedish Prescribed Drug Register contains data, with unique patient identifiers for all drugs prescribed and dispensed to the whole population of Sweden (more than 9 million inhabitants) since July 2005 [31]. The purchase of at least one prescription of a drug with an Anatomical Therapeutic Chemical (ATC)-code of NO6BA01NO6BA04 or NO6BA09 during the calendar year 2006, according to this register, was used to create the outcome variable of the study, consumption of ADHD medication (in the text also abbreviated as "medication").

There were considerable regional differences in the use of ADHD medication (see Table 1). Since these differences did not follow any obvious demographical or geographical patterns, we assumed that this pattern mirrored varying prescription routines in different counties, rather than variations in the prevalence of ADHD. A four-category variable, county category, with different levels of consumption was created to adjust the analysis to these regional differences. The counties were classified into four categories, according to the proportion of children who purchased ADHD prescription medications during 2006.

\section{Statistical analysis}

We used logistic regression to calculate odds ratios (OR) with $95 \%$ confidence intervals (CIs), for boys and girls separately, and with use of ADHD medication, defined above, as the outcome variable. In model 1 , we adjusted the analysis to three variables and considered confounders (age as a three-category variable (6-9 years, 10-15 years, 16-21 years), sex and county category).
For the boys, where the greater numbers of cases allowed this, we added maternal education and singleparent household as possible mediators/protective factors of adoption status in Model 2. Gender differences, in the effects of region of birth and age at adoption, on ADHD medication in adoptees were investigated in interaction analyses in models adjusted for age and county only. All statistical analyses were performed using SPSS version 15.0 for Windows.

\section{Results}

The most commonly purchased drug was methylphenidate $(88.6 \%)$, followed by atomoxetine $(9.2 \%)$ and amphetamine $(2.2 \%)$ with very similar patterns in adoptees compared with the non-adopted. The rates of medication were higher in international adoptees than in the majority population for both boys (3.83 vs $0.96 \%$ ) and girls (1.44 vs $0.27 \%$ ) (Table 1). These differences (adoptees vs. majority population and boys vs. girls) were present for all age groups (Fig. 1a, b). For boys, there was a peak at 16 years of age, where $8 \%$ of the adoptees compared with $1 \%$ in the majority population, had been prescribed an ADHD medication (Fig. 1a). The patterns were similar for adopted girls, but at a lower level, with a peak at 17 years of age and with a $3 \%$ rate of ADHD medication usage compared with $0.4 \%$ for the majority population (Fig. 1b).

As demonstrated in Table 2, the highest rates of ADHD medication were found in adopted boys, 10-15 years of age, which originated from Eastern Europe (12.6\%) and the Middle East/Africa (6.7\%). Adopted girls from Eastern Europe, 10-15 years of age, also had a high rate $(6.2 \%)$.

Internationally adopted boys from all regions of birth more often had ADHD medication compared to the majority population, but the ORs were particularly high for adoptees from Eastern Europe (OR 10.4 [8.7-12.4]), Middle East/Africa (OR 4.8 [2.6-8.7]) and Latin America (OR 3.6 [(2.8-4.5]) in the first model, adjusted for age and county of residency only (Table 3 ). Adding possible mediators/protective factors in Model 2 raised the ORs even more. Adopted girls had higher ORs compared to boys from the same region, with the highest OR being in girls from Eastern Europe (OR 15.4 [11.4-20.9]). In an interaction analysis of sex and adoption status, with all adoptees in one category, the $P$ value for this difference in effect on ADHD medication was 0.007 .

In an analysis of age at adoption, in international adoptees only, the ORs were higher for those adopted after infancy (Table 4). These ORs were similar for boys and girls with a $P$ value of 0.60 for interaction effects of being adopted as infant versus at an older age. 
Fig. 1 a ADHD medication $(\%)$ in male international adoptees and majority population peers of the same age. b ADHD medication (\%) in female international adoptees and majority population peers of the same age
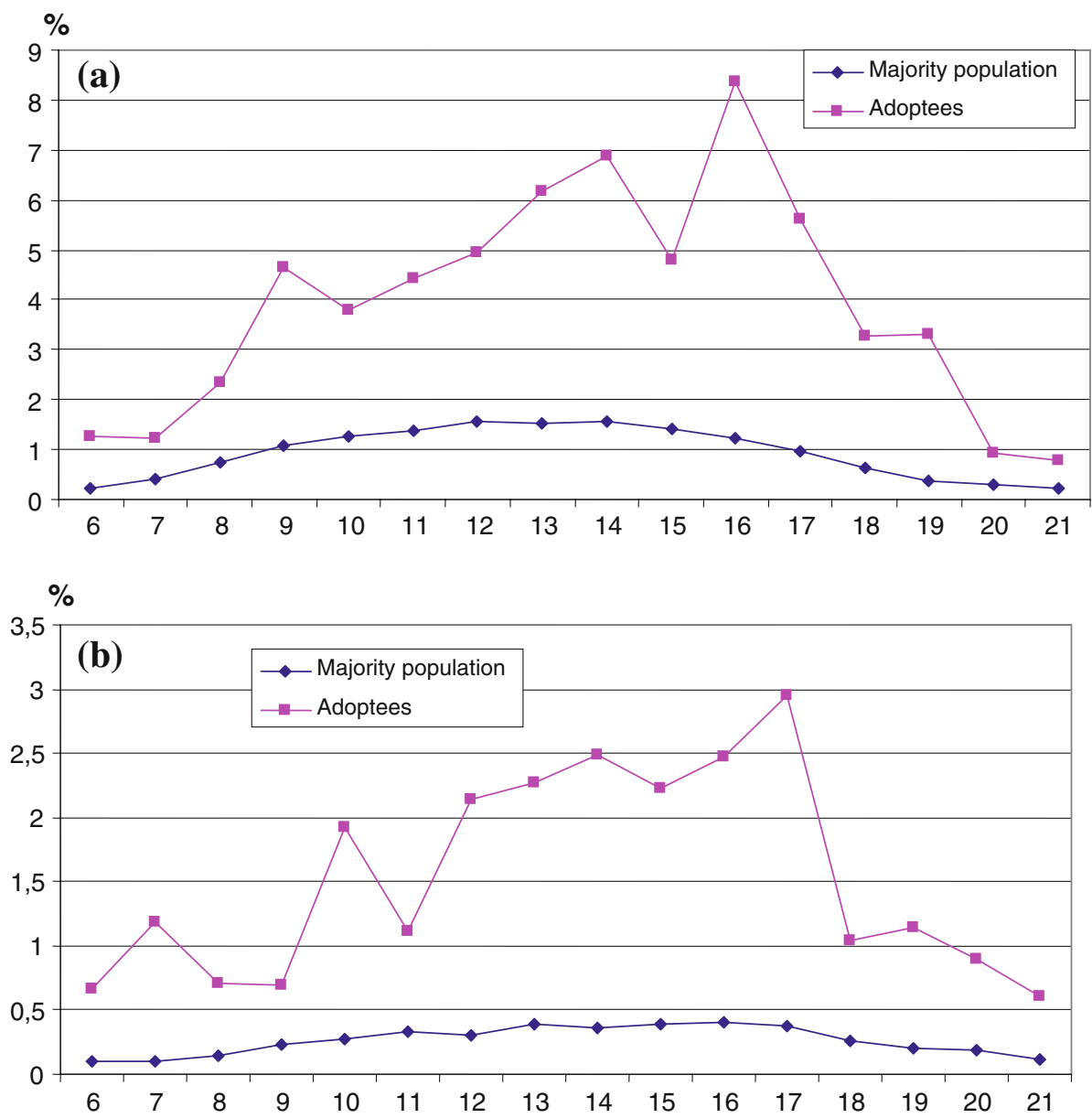

Table 2 Prevalence of ADHD medication based on sex, age and region of birth of the international adoptees

\begin{tabular}{|c|c|c|c|c|c|c|c|c|}
\hline & \multicolumn{4}{|l|}{ Boys } & \multicolumn{4}{|l|}{ Girls } \\
\hline & $N$ & $\begin{array}{l}6-9 \text { years } \\
\%\end{array}$ & $\begin{array}{l}10-15 \text { years } \\
\%\end{array}$ & $\begin{array}{l}16-21 \text { years } \\
\%\end{array}$ & $N$ & $\begin{array}{l}6-9 \text { years } \\
\%\end{array}$ & $\begin{array}{l}10-15 \text { years } \\
\%\end{array}$ & $\begin{array}{l}16-21 \text { years } \\
\%\end{array}$ \\
\hline Swedish majority & 680,949 & 0.6 & 1.5 & 0.7 & 645,141 & 0.1 & 0.3 & 0.3 \\
\hline Middle East/Africa & 372 & 2.0 & 6.7 & 2.0 & 366 & 1.8 & 2.3 & 1.7 \\
\hline Far East & 2,208 & 1.3 & 1.4 & 1.9 & 3,025 & 0.4 & 0.6 & 0.5 \\
\hline South Asia & 1,093 & 1.1 & 2.2 & 1.7 & 1,961 & 0.4 & 1.7 & 0.3 \\
\hline Latin America & 2,438 & 0.7 & 4.0 & 3.4 & 1,749 & 0.5 & 1.7 & 2.6 \\
\hline Eastern Europe & 1,666 & 5.8 & 12.6 & 7.8 & 1,256 & 2.5 & 6.2 & 2.3 \\
\hline All adoptees & 7,777 & 2.6 & 5.3 & 3.3 & 8,357 & 0.8 & 2.1 & 1.3 \\
\hline
\end{tabular}

\section{Discussion}

In this study, involving more than 16,000 international adoptees in a national cohort of 1,3 million Swedish residents in the ages 6-21 years, we found higher rates of ADHD medication in adopted boys (3.8\%) and girls (1.4\%), compared with non-adoptees (1.0 and $0.3 \%$, respectively). The risks were twofold and higher for adoptees, with those of Eastern European origin having the highest risk, and with a 12-fold increased risk in boys after adjustment for maternal education and single parenthood. The risk increased with higher age at adoption. To the best of our knowledge, this is the first study on ADHD medication in a population-based sample of international adoptees.

Our study demonstrates a gender pattern amongst adoptees similar to the general population, with greater prevalence of ADHD medication in boys. However, the 
Table 3 Logistic regression of adoption status, based on the region of birth and ADHD medication

\begin{tabular}{|c|c|c|c|}
\hline & \multicolumn{2}{|l|}{ Boys } & \multirow{2}{*}{$\begin{array}{l}\text { Girls } \\
\text { Model 1 } \\
\text { OR }(95 \% \text { CI })\end{array}$} \\
\hline & $\begin{array}{l}\text { Model } 1 \\
\text { OR (95\% CI) }\end{array}$ & $\begin{array}{l}\text { Model } 2 \\
\text { OR }(95 \% \text { CI) }\end{array}$ & \\
\hline $\begin{array}{l}\text { Swedish } \\
\text { majority }\end{array}$ & 1 & 1 & 1 \\
\hline $\begin{array}{l}\text { Middle } \\
\text { East/Africa }\end{array}$ & $4.8(2.6-8.7)$ & $5.3(2.8-10.0)$ & $9.6(4.2-21.6)$ \\
\hline Far East & $1.6(1.1-2.3)$ & $1.9(1.7-2.8)$ & $2.1(1.3-3.5)$ \\
\hline South Asia & $2.1(1.3-3.4)$ & $2.4(1.5-5.0)$ & $2.5(1.4-4.3)$ \\
\hline Latin America & $3.6(2.8-4.5)$ & $4.6(3.7-5.8)$ & $7.7(5.5-10.8)$ \\
\hline Eastern Europe & $10.4(8.7-12.4)$ & $12.5(10.4-14.9)$ & $15.4(11.4-20.9)$ \\
\hline
\end{tabular}

Model 1 is adjusted for age and county category

Model 2 is adjusted for age, county category, maternal education and single-parent household

Table 4 Age at adoption and ADHD medication

\begin{tabular}{llc}
\hline Age at adoption & $N$ & OR $(95 \%$ CI $)$ \\
\hline 0 & 5,704 & 1 \\
1 & 5,677 & $1.6(1.2-2.2)$ \\
$2-3$ & 3,197 & $2.5(1.8-3.4)$ \\
$4-7$ & 1,556 & $1.9(1.4-2.8)$
\end{tabular}

Model 1 is adjusted for age, sex, county category and region of birth

effect of being adopted on ADHD medication seemed to be stronger in girls than in boys. These results are in line with those found in another study on suicide attempts in the Swedish youth, where adopted girls were found to have greater increases in the relative risk than adopted boys [24]. We believe that these observations are due to environmental influences. The age-pattern in the use of ADHD medication was similar amongst adoptees and non-adoptees, probably reflecting common factors such as agedependent environmental demands and motivation aspects.

The increased risk of medication, observed in adoptees from Eastern Europe, represents the highest odds ratio for any negative health-related outcome found in a series of studies on the development of international adoptees. In a previous Swedish follow-up study of 76 adoptees from Poland, the former Soviet Union and Romania (about onethird from each region), maternal alcohol abuse was explicitly mentioned in the documents from the country of origin as the main reason for abandonment in more than one-third of the cases [20]. This suggests that foetal exposure to alcohol may have been an important factor in the development of ADHD of the adoptees from Eastern Europe in our study. It is reasonable to believe that genetic factors as well as other environmental factors may have contributed to the increased risk of ADHD medication too, but we have no data to support such hypotheses. The other odds ratios are of the same magnitude as in previously reported psychiatric outcomes and display a more favourable prognosis for children from Asia compared to Latin America $[3,4,7]$. The wide variation in outcomes amongst adoptees from different regions highlights the need for reporting the country of origin when presenting studies or reviews on the development of international adoptees.

Age of adoption is commonly regarded as a proxy for exposure to adversity during childhood [32]. Following this line, our results on age at adoption suggest that environmental factors to some degree have contributed to the formation, or the severity, of the ADHD symptoms. The lack of linearity (lower frequency in the oldest group than in the middle group) is probably due to the heterogeneity of the oldest group, also including children with sufficiently good first few years of life, but with emerging severe problems (like the death of a parent) later during childhood.

The main strength of this study is the large study group of adoptees representing whole national cohorts. The identification of this group was made possible through the utilisation of data from Swedish national registers, where prescriptions of drugs dispensed since July 2005 could be linked to these individuals. Universal and free access for all children to medical and psychiatric care in the Swedish health-care system also strengthens the conclusions of this study.

The use of national registers with pre-collected data provides certain limitations. For instance it is not possible to interview the individuals or collect complementary data, as all information in the national registers is unidentified; it is not possible to bring out any information linked to a certain individual.

The most important limitation of this study is probably the interpretation of the outcome variable, ADHD medication. In Sweden, the authority to prescribe stimulant medication in the management of ADHD is restricted to specialists with particular familiarity with the treatment of this disorder. Given this constraint, and in consideration of the access to free psychiatric care and the national guidelines mentioned above, we believe that medication prescription is a useful and fairly valid indicator of the more severe cases of ADHD in Sweden. However, a number of factors, apart from the severity of the disorder, are potential determinants of the usage patterns of ADHD medication. Factors within the health organisation are probably the most important of these determinants, illustrated by the differences among counties described in the "Methods" section. The existence of a few counties where medication rates are higher, and a few lower than the average county, suggests that other factors, apart from the severity of the disorder, determine whether medication is prescribed. Such 
factors could be associated with geographical differences in the availability of services for children with ADHD, and also with differences in the interpretation and implementation of the national guidelines in different local and regional Swedish health organisations. The fact that risk estimates were marginally affected by the inclusion of the county variable into the multivariate analysis, however, indicates that this variation was not an important source of bias in relation to the socio-economic variables in the study.

One may also speculate that child psychiatrists, consciously or unconsciously, have different prescription patterns for adoptees than for non-adoptees. Adoptive parents have a higher level of education than that of the majority population and also have higher than average financial resources. This should mean better propensity for the identification of ADHD and for seeking medical care. Along the same line, adoptive parents may be more sensitive to their children's behavioural problems. Given such circumstances, odds ratios of medication may be higher than the actual increased risk for ADHD. It may also be hypothesised that the greater social prerequisites amongst adoptive parents convey a potential for seeking and utilising psychological and educational support, thereby possibly making medication unnecessary. If so, the odds ratios of medication may underestimate the prevalence of ADHD. To the best of our knowledge, there is no study on adoptive parents' capacity to tolerate ADHD symptoms in the child and to adapt the environment to the needs of the child, factors that may also influence the rate of medication.

\section{Conclusion}

This study suggests that adoptees from Eastern Europe have a very high risk for ADHD medication. A structured identification and support programme should be tailored for this group. Adoptees from other regions have a more moderately increased risk, which should be communicated to adoptive parents and professionals who care for adoptees in their clinical practice.

Acknowledgments The research position of Frank Lindblad was financed by the Swedish Council for Working Life and Social Research.

\section{References}

1. Verhulst FC, Althaus M, Versluis-den Bieman HJ (1990) Problem behavior in international adoptees: I an epidemiological study. J Am Acad Child Adolesc Psychiatry 29:94-103

2. Tieman W, van der Ende J, Verhulst FC (2005) Psychiatric disorders in young adult intercountry adoptees: an epidemiological study. Am J Psychiatry 162:592-598
3. Hjern A, Lindblad F, Vinnerljung B (2002) Suicide, psychiatric illness and social maladjustment in inter-country adoptees in Sweden. The Lancet 360:443-448

4. Lindblad F, Hjern A, Vinnerljung B (2003) Inter-country adopted children as young adults-a Swedish cohort study. Am J Orthopsychiatry 73:190-202

5. Hjern A, Vinnerljung B, Lindblad F (2004) Avoidable mortality among child welfare recipients and intercountry adoptees-a national cohort study. J Epidemiol Community Health 58:412417

6. Vinnerljung B, Hjern A, Lindblad F (2006) Suicide attempts and severe psychiatric morbidity among former child welfare clientsa national cohort study. J Child Psychol Psychiatry 47:723-733

7. Elmund A, Lindblad F, Vinnerljung B, Hjern A (2007) Intercountry adoptees in out-of-home care-a national cohort study. Acta Paediatr 96:437-442

8. Pliszka S, AACAP Work Group on Quality Issues (2007) Practice parameter for the assessment and treatment of children and adolescents with attention-deficit/hyperactivity disorder. J Am Acad Child Adolesc Psychiatry 46:894-921

9. Wallis D, Russell HF, Muenke M (2008) Genetics of attention deficit/hyperactivity disorder. J Pediatr Psychol 33:1085-1099

10. Banerjee TD, Middleton F, Faraone SV (2007) Environmental risk factors for attention-deficit hyperactivity disorder. Acta Paediatr 96:1269-1274

11. Biederman J, Milberger S, Faraone SV et al (1995) Familyenvironment risk factors for attention-deficit hyperactivity disorder. A test of Rutter's indicators of adversity. Arch Gen Psychiatry 52:464-470

12. Biederman J, Faraone SV (2005) Attention-deficit hyperactivity disorder. The Lancet 366:237-248

13. O'Malley KD (1994) Fetal alcohol effect and ADHD. J Am Acad Child Adolesc Psychiatry 33:1059-1060

14. Bhatara V, Loudenberg R, Ellis R (2006) Association of attention-deficit hyperactivity disorder and gestational alcohol exposure: an exploratory study. J Atten Disord 9:515-522

15. Kreppner JM, O'Connor TG, Rutter M (2001) English, Romanian Adoptees Study Team Can inattention/overactivity be an institutional deprivation syndrome? J Abnorm Child Psychol 29:513528

16. Rutter M, O'Connor TG (2004) English, Romanian Adoptees (ERA) Study Team: are there biological programming effects for psychological development? Findings from a study of Romanian adoptees. Dev Psychol 40:81-94

17. Simmel C, Brooks D, Barth RP, Hinshaw SP (2001) Externalizing symptomatology among adoptive youth: prevalence and preadoption risk factors. J Abnorm Child Psychol 29:5769

18. Moore J, Fombonne E (1999) Psychopathology in adopted and nonadopted children: a clinical sample. Am J Orthopsychiatry 69:403-409

19. McGuinness TM, Pallansch L (2007) Problem behaviors of children adopted from the former Soviet Union. J Pediatr Health Care 21:171-179

20. Landgren M, Andersson Grönlund M, Elfstrand PO, Simonsson JE, Svensson L, Strömland K (2006) Health before and after adoption from Eastern Europe. Acta Paediatr 95:720-725

21. Grönlund MA, Aring E, Hellström A, Landgren M, Strömland K (2004) Visual and ocular findings in children adopted from eastern Europe. Br J Ophthalmol 88:1362-1367

22. Dalen M, Rygvold A-L (2006) Educational achievement in adopted children from China. Adopt Q 9:45-58

23. Odenstad A, Hjern A, Lindblad F, Rasmussen F, Vinnerljung B, Dalen M (2008) Does age at adoption and geographic origin matter? A national cohort study of cognitive test performance in adult intercountry adoptees. Psychol Med 38:1803-1814 
24. von Borczyskowski A, Hjern A, Lindblad F, Vinnerljung B (2006) Suicidal behaviour in national and international adult adoptees-a Swedish cohort study. Soc Psychiatry Psychiatr Epidemiol 41:95-102

25. Gibson AP, Bettinger TL, Patel NC, Crismon ML (2006) Atomoxetine versus stimulants for treatment of attention deficit/ hyperactivity disorder. Ann Pharmacother 40:1134-1142

26. Faraone SV, Biederman J, Morley CP, Spencer TJ (2008) Effect of stimulants on height and weight: a review of the literature. J Am Acad Child Adolesc Psychiatry 47:994-1009

27. Proos LA, Karlberg J, Hofvander Y, Tuvemo T (1993) Pubertal linear growth of Indian girls adopted in Sweden. Acta Paediatr 82:641-644

28. Vaughan B, Fegert J, Kratochvil CJ (2009) Update on atomoxetine in the treatment of attention-deficit/hyperactivity disorder. Expert Opin Pharmacother 10:669-676

29. Daughton JM, Kratochvil CJ (2009) Review of ADHD pharmacotherapies: advantages, disadvantages, and clinical pearls. J Am Acad Child Adolesc Psychiatry 48:240-248
30. Multi-generation register (2006) Statistics Sweden, background facts, population and welfare statistics 2007:3. A description of contents and quality

31. Wettermark B, Hammar N, Fored CM, Leimanis A, Otterblad Olausson P, Bergman U, Persson I, Sundström A, Westerholm B, Rosén M (2007) The New Swedish Prescribed Drug Registeropportunities for pharmacoepidemiological research and experience from the first six months. Pharmacoepidemiol Drug Saf 16:726-735

32. Dalen M, Lindblad F, Odenstad A, Rasmussen F, Vinnerljung B, Hjern A (2008) Educational attainment and cognitive competence in adopted men - a study of international and national adoptees, siblings and a general Swedish population. Child Youth Serv Rev 30:1211-1219 